Article

\title{
Estimating water content in water-oil mixtures and porous media they saturate: joint interpretation of NMR relaxometry and dielectric spectroscopy
}

\author{
Mariya Shumskayte *, Andrey Mezin, Elena Chernova, Aleksandra Burukhina, Nikita Golikov and Svetlana \\ Melkozerova
}

\begin{abstract}
Trofimuk Institute of Petroleum Geology and Geophysics, SB RAS, Geophysics division, 630090 Novosibirsk, Russia; shumskaitemi@ipgg.sbras.ru (M.S.); mezinaa@ipgg.sbras.ru (A.M.); ellenchernova@yandex.ru (E.C.); golikovna@ipgg.sbras.ru (N.G.); burukhinaai@ipgg.sbras.ru (A.B.); melkozerovasn@ipgg.sbras.ru (S.M.)

* Correspondence: shumskaitemi@ipgg.sbras.ru
\end{abstract}

\begin{abstract}
The article is devoted to the topical problem of estimating water content in water-oil mixtures and porous media they saturate, according to low-field NMR relaxometry and dielectric spectroscopy. The aim of the research is to theoretically substantiate and experimentally validate the capability of joint interpretation of data from these methods to acquire information on the filtration-volumetric properties of drill cuttings, relaxation characteristics of oil-containing fluids, water/oil ratio in water-oil mixtures and saturated with them drill cuttings in order to control the composition of liquids produced from boreholes. The studies were carried out on samples of cuttings and oils taken from fields in the northern and Arctic regions of the West Siberian oil-andgas province. Based on the experimental data obtained, we evaluated the water content in the wateroil mixtures, determined the main NMR parameters of the mixtures in terms of properties of the constituent oils, and specified the parameters and shapes of NMR and complex dielectric permittivity spectra. The NMR method was found to be effective in examining high-viscosity and medium-viscosity oils, while the dielectric spectroscopy method - in the study of light oils; their integration allows obtaining reliable data for all the samples under study. We also showed how the shapes of NMR and complex dielectric permittivity spectra depend on the rheological properties of oil belonging to the mixture.
\end{abstract}

Keywords: nuclear magnetic resonance, dielectric spectroscopy, water-oil mixture, relaxation characteristic, drill cuttings, West Siberia.

\section{Introduction}

The West Siberian oil-and-gas province is one of the largest petroleum-productive regions in the world and the richest petroleum province of Russia and the former Soviet Union [1]. Interest in its hydrocarbon (HC) prospects arose in scientific circles as early as in the 1930s, with the second half of the $20^{\text {th }}$ century in Russia being marked by the unequalled development of the West Siberian oil-and-gas complex [2]. However, the situation drastically changed at the beginning of the $21^{\text {st }}$ century, due to the high depletion of large discovered fields in the central part of the West Siberian province. For the purpose of maintaining the achieved hydrocarbon production volumes and ensuring the possibility of their increase, one of the top priorities for the oil-and-gas complex of Russia since then has been the formation of new centers of oil-and-gas production in its northern and Arctic parts. The creation of techniques that minimize costs and errors in the process of further geological development of these West Siberian regions is currently an urgent scientific and practical task. 
Water contamination in crudes may cause severe problems at any stage of petroleum production. Therefore, water testing is always a part of oil recovery and refining. Water can coexist in an oil sample as three phases: dissolved, emulsion, and free. The last two pose the greatest risk for industrial application and have to be always under control. There are various techniques for measuring water in oil [3]. They vary in methodological basis, extent of application, accuracy, time and labor expenditures. Further on, the most widely applied ones will be mentioned. The simplest technique is the visual crackle test, which is quick and easy but not quantitative, and whose results are not uniquely interpreted. Another way to determine water in oil is to apply saturation meters: the measurements are straightforward, accurate and require no solvents or special equipment. At the same time, with the use of such an approach, it is impossible to evaluate emulsion water or free water content, only dissolved water content being available. One more portable technique to obtain water concentration in oil is by means of calcium hydride test kits. The test provides a quantitative result, but accurate only down to $50 \%$ content of free or emulsion water in the sample. The Dean-Stark distillation and Karl Fischer coulometric titration are the most widely employed methods and the de facto standards of water-in-oil quantification [4-7]. The analysis performed by these procedures provides measurement of water in any state (dissolved, emulsion or free) and in any concentration: from near zero to $100 \%$. Significant difficulties associated with these techniques are both high time and labor expenditures, and requirement for laboratory equipment and solvents. Nowadays, the last and a most promising method of water-in-oil determination is infrared spectroscopy, characterized by a chemical-free and rapid analysis. However, its equipment is expensive and matching the results with those of the Karl Fischer titration calls for further investigations.

Along with that, such tasks can be addressed through analyzers based on the nuclear magnetic resonance (NMR) phenomenon. They allow an automatic express-control and analysis of raw materials' and oil products' parameters on a grand scale. The group of NMR methods is divided into strong-field NMR (high-resolution NMR) and low-field NMR. 'Low' magnetic fields are those with an intensity of less than $1 \mathrm{~T}$ (resonance frequency $<42 \mathrm{MHz}$ ) [8]. Today, low-field NMR is applied in various areas of science and industry. These are biotechnology and medicine [9], geophysical research [10], monitoring the distribution of cryogel in the environment when used to strengthen building structures in conditions of the Extreme North [11], studying the properties of hydrates of hydrocarbon gases, which are considered today as a promising hydrocarbon source $[12,13]$.

Concerning the petroleum industry, the NMR method is most widely utilized there in relation to evaluating the petrophysical parameters of rocks exposed by a borehole during nuclear magnetic logging, or those of rock samples of arbitrary shape and size (cores, drill cuttings) in laboratory examinations [14-17]. Every year, the issue of effective development of fields with hard-to-recover oil reserves is becoming increasingly urgent, many NMR works being devoted to high-viscosity oils and oil-saturated shales [18-21]. Today, interest is also growing in unconventional natural gas reserves; active work is underway on creating a methodology for identifying the main stages of gas hydrate dissociation from their NMR characteristics [12,13,22,23]. For formation fluids (liquid hydrocarbons, formation water, etc.), one can carry out their typification, component composition assessment [14,24-26], diffusion coefficient and viscosity estimation $[20,27,28]$. As for determining the composition of produced fluids with the conventional techniques, this is rather a complex technical problem that requires either separation of the mixture (at least gas separation), or deployment of one of the methods for accounting for the presence of gas in the mixture. In the NMR method, when measuring water content, dissimilar values of the nuclear relaxation time for water and oil protons are given consideration to, whereas gas content manifests itself in the amplitude of the measured signal only [29-31]. Moreover, the NMR method does not require sample preparation, has a multi-parameter analysis, and is explosion-, fire-, radiation- and toxic-proof. 
With advances in instrumentation technology and the appearance of new magnetic materials, the capabilities of NMR instruments are constantly growing and in perspective have great potential, including when combined with other methods, such as, for instance, dielectric spectroscopy. It is effective for analyzing such complex systems as organic and water systems, complex viscous liquids, polymers, microemulsions and oil dispersed systems. A combination of two dielectric spectroscopy methods (time-domain and frequency-domain) enables encompassing the frequency range from the micro- to terahertz region and scrutinize a wide range of substances in the temperature range from $-160^{\circ} \mathrm{C}$ to $+400^{\circ} \mathrm{C}$. Numerous studies have shown that in the frequency domain from units of kilohertz to units of gigahertz there can be pronounced a frequency dispersion of the complex dielectric permittivity (CDP), which some authors associate with a manifestation of the interlayer (intersurface) polarization at phase boundaries [32,33]. The paper [34] provides a comparative analysis of dielectric and NMR methods in examining the electrophysical parameters of a medium. It is shown that NMR may serve as an auxiliary tool for interpreting dielectric data.

Thus, the implementation of joint interpretation of NMR relaxometry and dielectric spectroscopy in appraising water-oil mixtures and drill cuttings they saturate will make it possible to control the composition of hydrocarbon and non-hydrocarbon mixtures produced from boreholes, as well as to determine in real time the filtration-volumetric properties of reservoirs under development.

Based on the obtained NMR data, we estimated the amount of water in water-oil mixtures, and, eventually, acquired their main NMR characteristics. The NMR-dataderived water contents in the mixtures are consistent with the actual ones. For drill cuttings saturated with the mixtures, the water content in the samples was retrieved from the NMR data at different water/oil ratios in the mixture. With the aid of dielectric spectroscopy, we found out the values of the real part of CDP to vary proportionally to the amount of water in the sample.

\section{Research methods and sample preparation}

The study was carried out via the standard set of organic geochemistry laboratory methods, pulsed NMR relaxometry and dielectric spectroscopy, with a comparative analysis of data from these methods.

NMR measurements were made on the MST-05 relaxometer with an operating frequency of 2,2 $\mathrm{MHz}$ and a magnetic field of 0,05 $\mathrm{T}$ [35]. The technique is based on recording the decay of nuclear magnetization from a hydrogen-containing sample and allows for determining the total hydrogen content of a fluid or rock, pore size distribution, viscosity, and component composition of the fluid under analysis [14,36]. Processing and interpretation of the initial NMR signal (relaxation curve) consists in the inverse transformation of the signal into the spectrum of transverse relaxation times $\mathrm{T}_{2}$ [37-39]. This procedure is reduced to solving the Fredholm integral equation of the second kind. The inverse problem is solved by the Tikhonov regularization method [40]. The obtained NMR spectrum is further analyzed and employed for a quantitative and qualitative interpretation $[12,24,25,41]$.

CDP measurements were performed in the frequency range $100 \mathrm{~Hz}-5 \mathrm{MHz}$ in a capacitor cell with the LCR GWInstek meter (Taiwan). The measurement procedure is a modification of the classical technique for measuring the dielectric permittivity in a flat capacitor [42]. The diameter of the cell electrodes is selected such that the field in the central part of the capacitor, where the sample under investigation is placed, is uniform. At the stage of determining CDP values, the sample is located in the experimental cell in the form of a flat capacitor with an electrode diameter of $28 \mathrm{~mm}$, and $10 \mathrm{~mm}$ interelectrode distance. The cell is connected by wires to the LCR-78105G measuring device with an operating frequency range of 0,02-5,000 kHz. After obtaining the impedance components, the values of the capacitance for the empty cell are calculated, and then for that with the 
sample. The data obtained are made use of to find CDP values at the corresponding frequency $[34,43]$.

From a thermodynamic point of view, water-oil mixtures belong to unstable systems that strive to achieve an equilibrium state with a minimum interface area. Therefore, the main indicator in this context is their stability, i.e. the ability not to disintegrate and delaminate for a certain time that depends on the physicochemical properties of the constituent fluids.

To prepare water-oil mixtures and afterwards saturate drill cuttings, we applied 4 oil samples (B, C, D, E) and 1 condensate sample (A), taken from the Jurassic-Cretaceous deposits of West Siberian fields (Table 1). The samples selected are characterized by a wide range of physicochemical properties (Table 1): density (from 0,7751 to $0,9365 \mathrm{~g} / \mathrm{cm}^{3}$ ), dynamic viscosity (from 0,92 to $34,53 \mathrm{MPa} \cdot \mathrm{s}$ ), content of saturated and aromatic hydrocarbons (from 83,7 to $99,8 \%$ ), as well as of resinous-asphaltic components (from 16,3 to $0,2 \%$ ). The listed characteristics were determined by the standard organic geochemistry laboratory methods. More specifically, the density of the samples $\left(\mathrm{kg} / \mathrm{m}^{3}\right)$ was measured at $20^{\circ} \mathrm{C}$ with the VIP-2MR vibration density meter [44]; kinematic viscosity $\left(\mathrm{mm}^{2} / \mathrm{s}\right)$ at $20^{\circ} \mathrm{C}$ - with the Pinkevitch viscometers of various configurations [45]; dynamic viscosity (MPa-s) - by means of recalculation from the kinematic viscosity [45]; group hydrocarbon composition - by column liquid chromatography after separating the asphaltenes.

Table 1. Characteristics of the hydrocarbon fluids used in the study: oils and condensate from the fields of West Siberia.

\begin{tabular}{cccccc}
\hline & & & & \multicolumn{2}{c}{ Group composition (mass \%) } \\
\cline { 5 - 6 } Sample & Field & $\begin{array}{c}\text { Density, } \\
\mathbf{g} / \mathbf{c m}^{3}\end{array}$ & $\begin{array}{c}\text { Dynamic } \\
\text { viscosity, MPa·s }\end{array}$ & $\begin{array}{c}\text { Content of } \\
\text { saturated and } \\
\text { aromatic } \\
\text { hydrocarbons }\end{array}$ & $\begin{array}{c}\text { Content of } \\
\text { resins and } \\
\text { asphaltenes }\end{array}$ \\
\hline A & Salmanovkkoye & 0,7751 & 0,92 & 99,8 & 0,2 \\
B & Salymskoye & 0,8153 & 3,11 & 97,1 & 2,9 \\
C & Pravdinskoe & 0,8331 & 5,03 & 98,7 & 1,3 \\
D & Pravdinskoe & 0,8632 & 6,51 & 86,9 & 13,1 \\
E & Russkoye & 0,9365 & 34,53 & 83,7 & 16,3 \\
\hline
\end{tabular}

On the basis of each of the 5 hydrocarbon fluid samples, 5 oil-water mixtures were prepared (Table 2). Immediately before the measurements on the NMR relaxometer, the specified volumes of distilled water and oil/condensate (dry) were homogenized with a mixer for 2 minutes, after which they were placed to stand at room temperature for 1 minute. With this approach, the authors tried to get samples of water-oil mixtures containing dissolved, emulsion, and free water.

Table 2. Sample compositions for the water-oil mixtures.

\begin{tabular}{cccc}
\hline Sample name & Sample composition & Sample name & Sample composition \\
\hline Water & Distilled water & D1 & $90 \%$ oil D+10\% water \\
A1 & $90 \%$ oil A+10\% water & D2 & $80 \%$ oil D+20\% water \\
A2 & $80 \%$ oil A+20\% water & D3 & $70 \%$ oil D+30\% water \\
A3 & $70 \%$ oil A+30\% water & D4 & $60 \%$ oil D+40\% water \\
A4 & $60 \%$ oil A+40\% water & D5 & $50 \%$ oil D+50\% water \\
A5 & $50 \%$ oil A+50\% water & E1 & $90 \%$ oil E+10\% water \\
B1 & $90 \%$ oil B+10\% water & E2 & $80 \%$ oil E+ $20 \%$ water \\
B2 & $80 \%$ oil B+20\% water & E3 & $70 \%$ oil E+30\% water \\
B3 & $70 \%$ oil B+30\% water & E4 & $60 \%$ oil E+40\% water \\
B4 & $60 \%$ oil B+40\% water & E5 & $50 \%$ oil E+50\% water \\
B5 & $50 \%$ oil B+50\% water & &
\end{tabular}




\begin{tabular}{ll} 
C1 & $90 \%$ oil C+10\% water \\
C2 & $80 \%$ oil $\mathrm{C}+20 \%$ water \\
C3 & $70 \%$ oil C+30\% water \\
C4 & $60 \%$ oil C+40\% water \\
C5 & $50 \%$ oil C $+50 \%$ water \\
\hline
\end{tabular}

For the study of the filtration-volumetric properties, 7 samples of drill cuttings were taken from the 960-1,040 m depth interval from the Medvezhye oil-gas-condensate field, confined to the Nadym-Pursk petroleum region in the northeastern part of the West Siberian oil-and-gas province (Table 3).

Table 3. Lithological description of the drill cuttings.

\begin{tabular}{|c|c|c|c|}
\hline $\begin{array}{l}\text { Sample } \\
\text { number }\end{array}$ & $\begin{array}{c}\text { Sampling } \\
\text { depth, } \mathrm{m}\end{array}$ & $\begin{array}{c}\phi(\mathrm{NMR}), \\
\% \\
\end{array}$ & Lithological description \\
\hline 1 & 960 & 13,21 & $\begin{array}{l}\text { argillaceous siltstone with interbedded mudstone, } \\
\text { carbonatized, with HC smell }\end{array}$ \\
\hline 2 & 970 & 18,71 & $\begin{array}{l}\text { argillaceous siltstone with interbedded mudstone, } \\
\text { carbonatized, with HC smell }\end{array}$ \\
\hline 3 & 1,000 & 15,11 & $\begin{array}{l}\text { argillaceous siltstone with interbedded mudstone, } \\
\text { carbonatized, with HC smell }\end{array}$ \\
\hline 4 & 1,010 & 17,36 & $\begin{array}{l}\text { argillaceous siltstone with interbedded mudstone, } \\
\text { carbonatized, with HC smell }\end{array}$ \\
\hline 5 & 1,020 & 14,57 & $\begin{array}{l}\text { argillaceous siltstone with interbedded mudstone, } \\
\text { carbonatized, with HC smell }\end{array}$ \\
\hline 6 & 1,030 & 13,99 & $\begin{array}{l}\text { argillaceous siltstone with interbedded mudstone, } \\
\text { carbonatized, with HC smell }\end{array}$ \\
\hline 7 & 1,040 & 19,52 & medium-grained sand admixed with carbonates \\
\hline
\end{tabular}

At the first stage of sample preparation, the drill cuttings were washed out by hot extraction with chloroform for 3-4 days. This was followed by holding the samples in an oven at a temperature of $105{ }^{\circ} \mathrm{C}$ over 24 hours for complete evaporation of the solvent. Then the samples were placed in $45 \mathrm{~cm}^{3}$ containers and filled with distilled water up to the middle of the sample height, and set under vacuum for 24 hours to remove air bubbles at the bottom of the container. After that, water was added to the edges of the container, and the samples were set under vacuum for another 5 days until complete saturation. At the subsequent stage, the samples were put in an oven to evaporate excess moisture and achieve the required water content by mass relative to the dry and $100 \%$ water-saturated samples. Upon reaching the sought-for water content, the samples were saturated with oil according to the same scheme. In this way, we obtained the drill cuttings samples with a given oil/water ratio (50/50, 70/30 and 90/10).

\section{NMR investigations}

\subsection{NMR studies of water-oil mixtures}

Following the results of the experimental NMR studies, $T_{2}$ spectra were derived for each sample. Figure 1 shows the spectra for the most representative samples prepared on the basis of the oils with very different viscosity and density (Table 1). With an increase in the water content in the light- and medium-oil-based mixtures, the spectra shift towards large $\mathrm{T}_{2}$ times. As concerns those based on the heavy oils, the positions of the spectra on the relaxation time axis change insignificantly, while the amplitude of the peaks varies in proportion to the oil/water ratio in the mixture. 


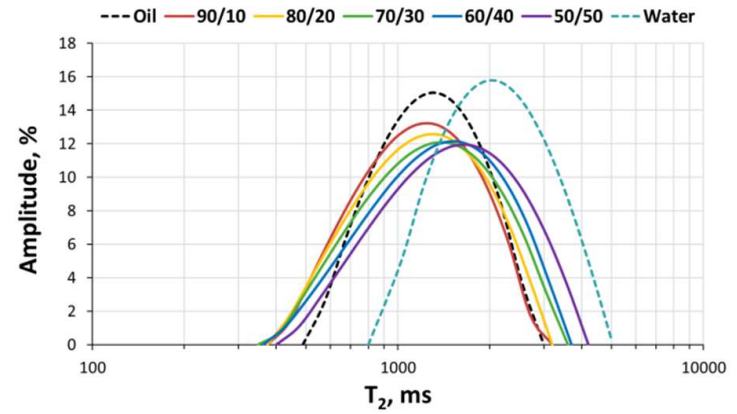

(a)

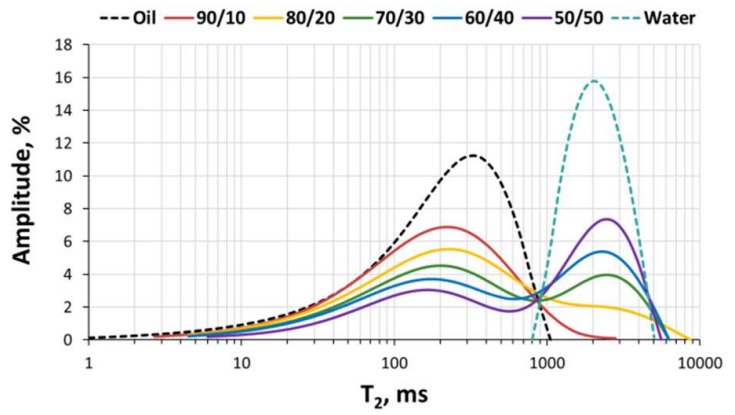

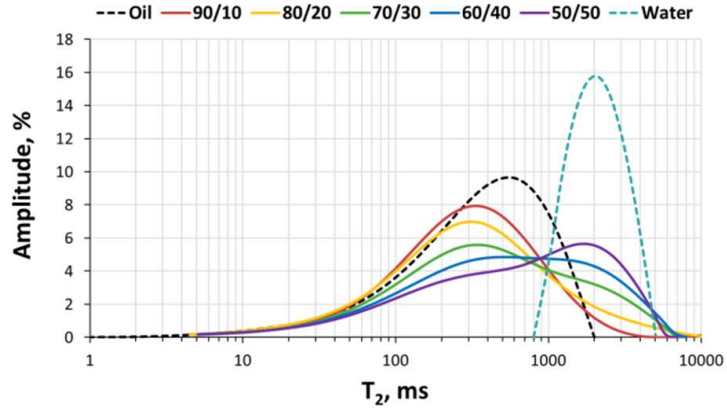

(b)

(c)

Figure 1. Transverse relaxation time spectra for the water-oil mixtures: (a) A1-A5; (b) C1-C5; (c) D1-D5.

The graphs indicate that the spectra of the light-oil-based mixtures (Figure 1a) have a unimodal form at any water content (10-50\%), the average $\mathrm{T}_{2}$ value being 1,000-1,500 ms; the spectra of the mixtures intersect with that of distilled water at the point of the maximum amplitude. The spectra of the heavy-oil-based mixtures (Figure 1c) are bimodal when the water content in the sample exceeds $20 \%$, with the maximum peaks at the relaxation times of free oil (150-200 ms) and distilled water (2,000-2,500 ms), respectively. The oil and water spectra virtually do not intersect; the separation of the peaks is observed at relaxation times of the order of 1,000 ms. In this case, the amplitude of the water-related peak increases in proportion to the water content growth in the mixture. Regarding the spectra of the mixtures based on the medium-viscosity oil (Figure 1b), they have a unimodal form with the water content in the sample up to $30 \%$; when the content exceeds $30 \%$, an 'inflection' appears in the region of 1,000 ms. The oil and water spectra intersect at $1,500 \mathrm{~ms}$.

In order to find water content in the mixtures from NMR measurements, we proposed to consider the integral area under that part of the mixture spectrum, which is to the right of the intersection point of the water and mixture spectra. The calculation results for all the samples are displayed in Table 4 . The average calculation error is $21 \%$.

Table 4. Water content in the water-oil mixtures: actual and calculated from NMR data.

\begin{tabular}{cccccc}
\hline $\begin{array}{c}\text { Sample Actual water content } \\
\text { number }\end{array}$ & $\begin{array}{c}\text { Water content } \\
\text { in the sample, \% } \\
\text { NMR data, \% }\end{array}$ & $\begin{array}{c}\text { Sample } \\
\text { number Actual water content } \\
\text { in the sample, \% }\end{array}$ & $\begin{array}{c}\text { Water content } \\
\text { calculated from } \\
\text { NMR data, \% }\end{array}$ \\
\hline A1 & 10 & 17 & C4 & 40 & 27 \\
A2 & 20 & 32 & C5 & 50 & 26 \\
A3 & 30 & 42 & D1 & 10 & 6
\end{tabular}




\begin{tabular}{llclll} 
A4 & 40 & 44 & D2 & 20 & 19 \\
A5 & 50 & 55 & D3 & 30 & 28 \\
B1 & 10 & 8 & D4 & 40 & 38 \\
B2 & 20 & 16 & D5 & 50 & 50 \\
B3 & 30 & 27 & E1 & 10 & 15 \\
B4 & 40 & 35 & E2 & 20 & 22 \\
B5 & 50 & 37 & E3 & 30 & 36 \\
C1 & 10 & 6 & E4 & 40 & 49 \\
C2 & 20 & 11 & E5 & 50 & 62 \\
C3 & 30 & 24 & & & \\
\hline
\end{tabular}

\subsection{NMR studies of drill cuttings at mixed saturation}

On the drill cuttings samples (Table 3 ) saturated with the mixtures from oils $\mathrm{C}$ and E, NMR measurements were performed at a given saturation: 50/50, 70/30 and 90/10 (Figure 2). For the mixture associated with oil E, we did not manage to obtain a saturation of 70/30, since the authors were limited in the volumes of high-viscosity oils. For clarity, the graphs exhibit the spectrum of the drill cuttings saturated with distilled water. It is unimodal with $\mathrm{T}_{2}$ times $<100 \mathrm{~ms}$, the maximum amplitude of the spectrum occurring at a relaxation time of $\approx 10 \mathrm{~ms}$.

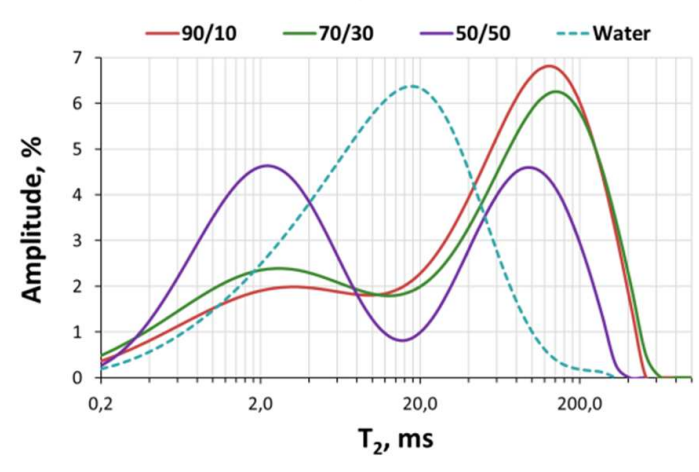

(a)

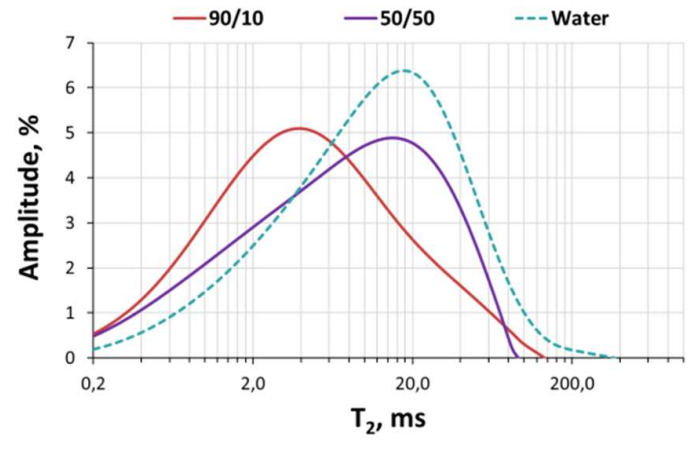

(b)

Figure 2. Transverse relaxation time spectra for the drill cuttings sampled from the $1010 \mathrm{~m}$ depth and saturated with water-oil mixtures: (a) based on oil C; (b) based on oil E.

The drill cuttings saturated with the oil-C-based mixture are characterized by bimodal spectra with a clear peak separation at 50/50 saturation, and by a smooth inflection at 70/30 and 90/10 saturations (Figure 2a). In this case, the inflection point and/or the separation point of the spectrum into 2 peaks lies in the region of $10 \mathrm{~ms}$. With the rising water content in the mixture, the spectra shift, albeit insignificantly, to the right, and their amplitude increases. The saturation spectra of 70/30 and 90/10 differ slightly, which may indicate the real oil saturation percentages in these samples to be close and differ from the 50/50 saturation by about 2 times. The cuttings with the oil-E-based mixture are distinguished by unimodal spectra without inflections (Figure 2b). Meanwhile, the spectrum of the sample with a higher water content is located to the left on the $\mathrm{T}_{2}$ axis, while the spectra of the completely water- and oil-saturated ( $90 \%$ oil) samples vary inconsiderably. This is apparently because when interacting in the pore space of the sample, water and oil have similar relaxation characteristics, despite the fact that in a free state these characteristics are substantially different. In turn, it complicates phase separation at the mixed saturation and does not allow the water/oil content in a sample to be calculated from NMR data.

As provided by the described above methodology - through the intersection point of the water and mixture spectra but regarding the saturation with oil (since the spectrum is 
to the right of the water spectrum) - we calculated the saturations of the cuttings from NMR data and matched them against the mass-derived saturation values (Table 5). One can see that from NMR data the 70/30 and 90/10 saturations are determined most accurately (average error being 16\%).

Table 5. Oil saturation of the drill cuttings (oil C), calculated by mass and NMR data.

\begin{tabular}{ccccccc}
\hline \multirow{2}{*}{$\begin{array}{c}\text { Sampling } \\
\text { depth , } \mathbf{m}\end{array}$} & \multicolumn{2}{c}{ Oil saturation from NMR data, $\%$} & \multicolumn{3}{c}{ Oil saturation calculated by mass, $\%$} \\
\hline 960 & $50 / 50$ & $70 / 30$ & $90 / 10$ & $50 / 50$ & $70 / 30$ & $90 / 10$ \\
\hline 970 & 40,5 & 64,5 & 72,1 & 19,3 & 40,1 & 47,5 \\
1,000 & 37,0 & 51,1 & 64,4 & 22,3 & 40,1 & 54,8 \\
1,010 & 34,9 & 45,8 & 60,1 & 35,8 & 45,5 & 64,4 \\
1,020 & 29,1 & 53,4 & 56,8 & 28,0 & 46,4 & 46,3 \\
1,030 & 29,2 & 47,1 & 62,2 & 16,9 & 49,0 & 45,9 \\
1,040 & 32,7 & 55,2 & 63,2 & 28,9 & 47,6 & 51,6 \\
\hline
\end{tabular}

\section{Dielectric studies of drill cuttings}

Following the results of the experimental study, the CDP spectra were obtained for all the drill cuttings samples (Table 3 ). Figure 3 displays the most representative spectra of the real part of $\operatorname{CDP}\left(\varepsilon^{\prime}\right)$ for the samples saturated with the oil-water mixture related to oils $\mathrm{C}$ and $\mathrm{E}$ (Table 1).
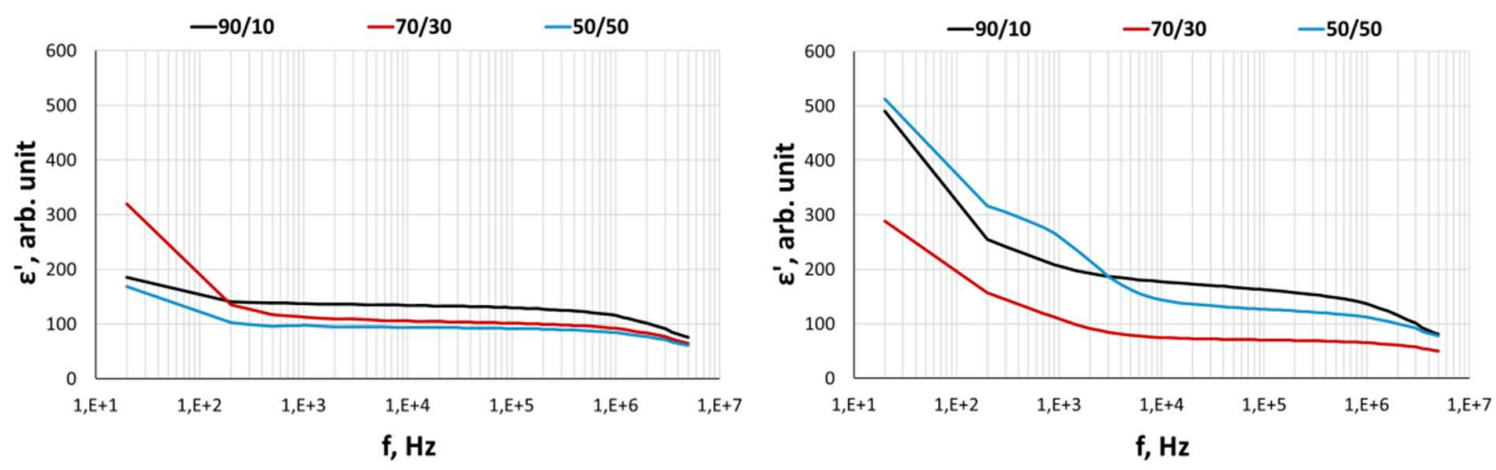

(a) 

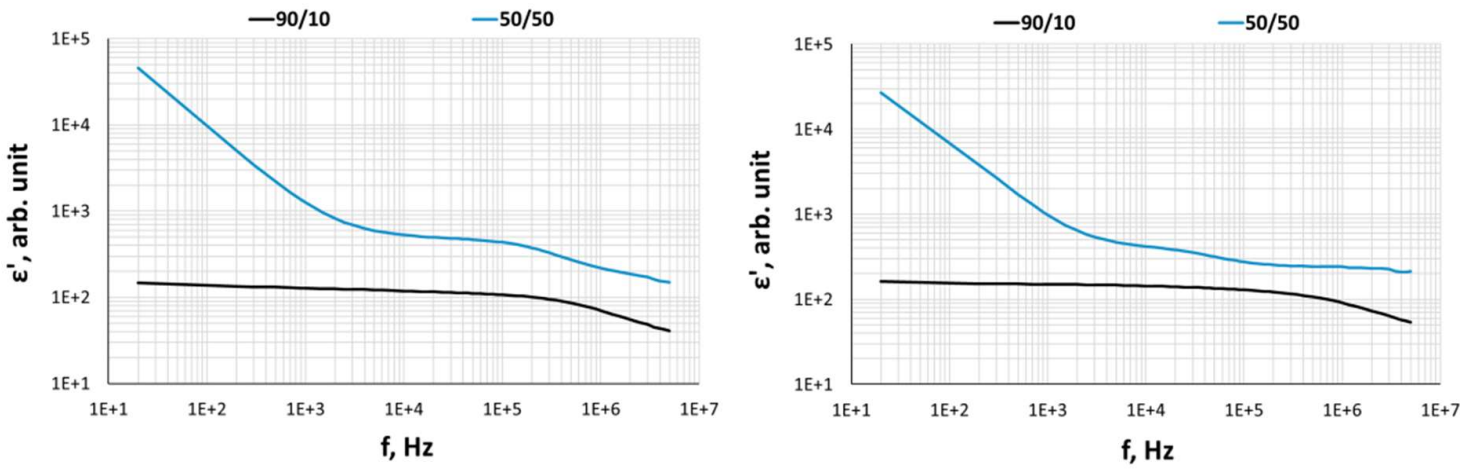

(b)

Figure 3. Spectra of the real part of CDP for the drill cuttings from 960 (left) and 970 (right) m depths, saturated with water-oil mixtures: (a) based on oil C; (b) based on oil E.

The graphs demonstrate that for the sample with the high-viscosity oil E (Figure 3b), the real part of CDP increases with the growing water content in the sample. Accordingly, in the high-frequency region $(\mathrm{f}=1 \mathrm{MHz})$ it regularly grows larger by about 3 times $(70-$ 220 rel. units for the sample from $960 \mathrm{~m}$ and 90-240 rel. units for the sample from $970 \mathrm{~m}$ ). When the samples are saturated with the oil-C-based oil-water mixture (Figure 3a), an unambiguous conclusion cannot be drawn, since the behavior of the curves is irregular. Perhaps this is for the reason that the density of oil C differs from that of distilled water so much that the liquids in the pore space of the sample do not form a single system. Instead, they are present in the pores, for example, in the form of oil droplets in the void space, whereas the water is adjacent to the grain surface. Such being the case, the oil and water separately contribute to the overall signal. In this regard, there is an additional relaxation in a frequency range of $1 \mathrm{kHz}$ in the spectra of the real part of CDP for the sample from $970 \mathrm{~m}$; this effect has been observed by many researchers [46,47]. Such relaxation is valid only for the samples saturated with light oil C; for those with heavy oil E a similar effect is not evidenced. It seems not to be possible to estimate the amount of water/oil in the sample, because the liquids in the pore space manifest themselves differently in the spectra.

The graph in Figure 4 gives the dependence of the real part of CDP on the water content. For the samples saturated with the mixture from heavy oil $\mathrm{E}$, the value consistently goes up with the growing water content. As for the samples based on light oil C, the type of the dependence changes with the water content exceeding $10 \%$. Presumably, at such a water content, the saturating fluid transforms into a mixture in which a further increase in the water content leads to a uniform growth of the analyzed signal. 


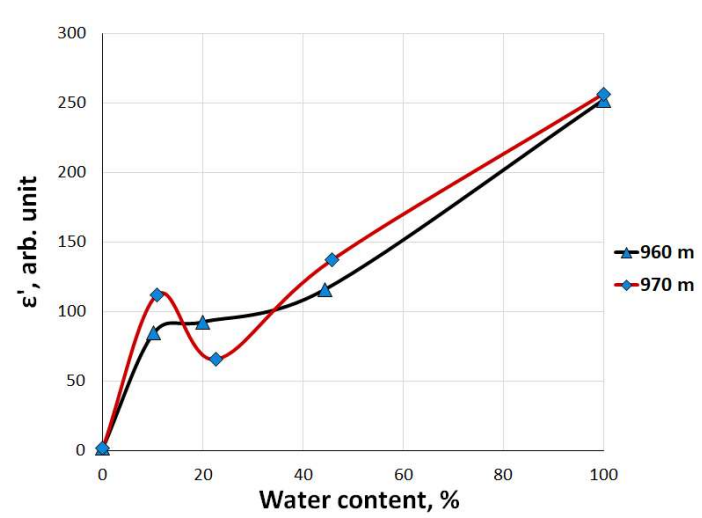

(a)

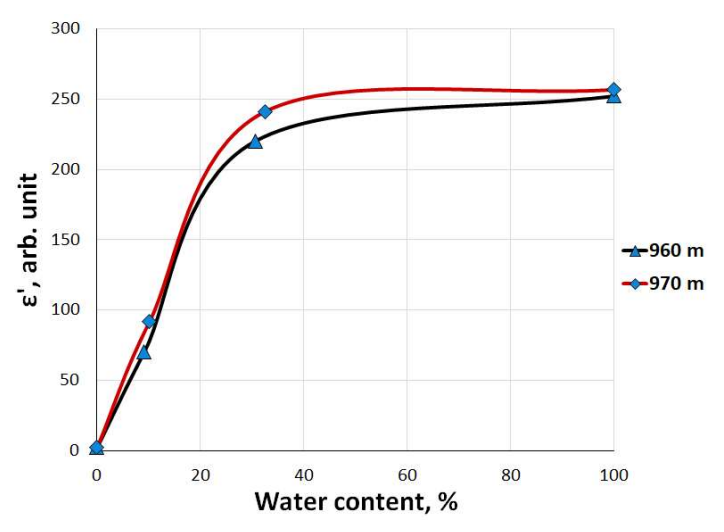

(b)

Figure 4. Dependences of the real part of CDP (at $1 \mathrm{MHz}$ ) on the water content for the drill cuttings from 960 and $970 \mathrm{~m}$ depths, saturated with water-oil mixtures: (a) based on oil C; (b) based on oil E.

Examinations of the dielectric characteristics of the water-oil mixtures were not carried out, since the geometric parameters of the available experimental cell do not allow measurements of liquid samples with a large real part of CDP as in distilled water $(\varepsilon=80$ rel. units). To conduct such investigations, the necessary experimental cell has been designed and is currently under development.

\section{Conclusions}

The research was aimed at the experimental confirmation of joint interpretation of NMR relaxometry and dielectric spectroscopy data when studying the filtrationvolumetric properties of drill cuttings and NMR characteristics of oil-containing reservoir fluids, as well as assessing the amount of water in water-oil mixtures and porous media they saturate. The NMR method was shown to be applicable to the study of water-oil mixtures. Viscous-oil-based mixtures are characterized by bimodal spectra of transverse relaxation times, whereas light-oil-based ones are marked by unimodal spectra or having a slight inflection. With a growth in the water content in the mixture, the spectra shift towards large relaxation times for the mixtures based on light and medium oils. However, for those based on heavy oils, the position of the spectra on the relaxation time axis changes insignificantly, while the amplitude variates proportionally to the water/oil content in the mixture. To estimate the water content from NMR, we proposed to consider the area under that part of the mixture spectrum, which is to the right of the intersection point with the distilled water spectrum, the average calculation error being $21 \%$.

The NMR experiments on drill cuttings give the opposite picture: the spectra are unimodal when the mixture is based on viscous oil, and bimodal in the case of mediumviscosity-oil. For the cuttings partially saturated with light oil, the error in calculating the water content does not exceed $20 \%$. As reported by the dielectric spectroscopy data, the samples saturated with a heavy-oil-based mixture exhibit a regular increase in the real part of the complex dielectric permittivity with the rising water content. Concerning the light-oil-based samples, this dependence changes sharply when the water content is more than $10 \%$.

We experimentally established the NMR relaxometry method to be effective for determining water content in water-oil mixtures based on high-viscosity and medium oils, as well as in samples of saturated with them drill cuttings. Dielectric spectroscopy, on the other hand, gives reliable results when studying cuttings partially saturated with light oil. Thus, with the joint interpretation of these methods, it is possible to obtain reliable data on the water content in hydrocarbon fluids over a wide range of their physicochemical properties. 
Later on, the attained results can make it possible to monitor the composition of hydrocarbon and non-hydrocarbon mixtures produced from boreholes, as well as to evaluate the petrophysical parameters of reservoirs under development on a real-time basis.

Author Contributions: Conceptualization, M.Sh.; methodology, M.Sh., A.M. and N.G.; investigation, A.M., A.B. and E.Ch.; writing-original draft preparation, M.Sh., N.G., A.M., A.B., E.Ch. and S.M; writing - review and editing, M.Sh., A.M., A.B., E.Ch. and N.G.; supervision, M.Sh.; project administration, M.Sh.; funding acquisition, M.Sh. All authors have read and agreed to the published version of the manuscript.

Funding: The research was funded by RFBR and Novosibirsk region, project number 20-45-540002.

Institutional Review Board Statement: Not applicable.

Informed Consent Statement: Not applicable.

Data Availability Statement: The data presented in this study are available on request from the corresponding author. The data are not publicly available due to the new line of research.

Acknowledgments: The authors are grateful to Vladimir A. Cheverda and Vyacheslav Glinskikh for offering to publish this article in this special issue.

Conflicts of Interest: The authors declare no conflict of interest.

\section{References}

1. Ulmishek G.F. Petroleum geology and resources of the West Siberian Basin, Russia. US Geological Bulletin 2201-G, 2003, 53 p.

2. Komgort, M.V. The problem of Siberian oil in scientific polemics during the period from 1920 to 1930. Bulletin of the Tyumen State University, 2010, No. 1, pp. 90-95.

3. Rajinder, P. Techniques for measuring the composition (oil and water content) of emulsions - a state of the art review. Colloids and Surfaces A: Physicochemical and Engineering Aspects 1994, 84, pp. 141-193. https://doi.org/10.1016/0927-7757(93)02711-M.

4. ASTM D95-13(2018), Standard Test Method for Water in Petroleum Products and Bituminous Materials by Distillation, ASTM International, West Conshohocken, PA, 2018, www.astm.org

5. ASTM D6304-20, Standard Test Method for Determination of Water in Petroleum Products, Lubricating Oils, and Additives by Coulometric Karl Fischer Titration, ASTM International, West Conshohocken, PA, 2020, www.astm.org

6. GOST 2477-2014, Petroleum and petroleum products. Method for determination of water content, Interstate Council for Standardization, Metrology and Certification, Minsk, 2018 (In Russian).

7. GOST R 54281-2010, Petroleum products, lubricating oils and additives. Test method for determination of water by coulometric Karl Fischer titration, Federal Technical Regulation and Metrology Agency, Moscow, 2019 (In Russian).

8. Mitchell, J.; Gladden, L.F.; Chandrasekera, T.C.; Fordham, E.J. Low-field permanent magnets for industrial process and quality control. Progress in Nuclear Magnetic Resonance Spectroscopy 2014, 76, 1-60. https://doi.org/10.1016/j.pnmrs.2013.09.001.

9. Nikolaeva, T.N.; Fatrakhmanova, Yu.A.; Gizzatullina, A.Sh.; Skirda, V.D. Development of new methodological approaches to the problem of cancer diagnostics based on using the possibilities of magnetic resonance methods in studying the properties of albumin molecules. Polzunovsky almanac 2010, 2, 289-291 (In Russian).

10. Kataev, R.S.; Idiyatullin, Z.Sh.; Temnikov, A.N.; Khayrullina, I.R. Universal multi-parametric express analyzer of fuels, oils and natural bitumens based on the nuclear magnetic resonance method. Modern scientific technologies 2008, 5, 58 (In Russian).

11. Altunina, L.K.; Gan-Erdene, T.; Rozhdestvensky, E.A.; Svarovskaya, L.I.; Filatov, D.A.; Fufaeva, M.S. Change in soil properties under the influence of cryogel. Soil science, 2014, 5, 563-570. https://doi.org/10.7868/S0032180X1401002X.

12. Turakhanov, A.H.; Shumskayte, M.Y.; Ildyakov, A.V.; Manakov, A.Y.; Smirnov, V.G.; Glinskikh, V.N.; Duchkov, A.D. Formation of methane hydrate from water sorbed by anthracite: An investgation by low-field NMR relaxation. Fuel 2020, 262, 1-6. https://doi.org/10.1016/j.fuel.2019.116656.

13. Shumskayte, M.Y.; Manakov, A.Y.; Sagidullin, A.K.; Glinskikh, V.N.; Podenko, L.S. Melting of tetrahydrofuran hydrate in pores: An investigation by low-field NMR relaxation. Marine and Petroleum Geology 2021, 129, 1-5. https://doi.org/10.1016/j.marpetgeo.2021.105096.

14. Coates, G.; Xiao, L.; Prammer, M. NMR logging. Principles and application; Houston: Halliburton energy Services, 2001,342 p.

15. Flaum, M.; Hirasaki, G.J.; Flaum, C.; Straley, C. Measuring pore connectivity by pulsed field gradient diffusion editing with hydrocarbons gases. Magnetic Resonance Imaging, 2005, 23, 337-339. https://doi.org/10.1016/j.mri.2005.01.002.

16. Mirotchnik, K.; Kantzas, A.; Starosud, A.; Aikman, M. A New method for group analysis of petroleum fractions in unconsolidated porous media. Journal of Canadian Petroleum Technology, 2001, 40, 38-44. https://doi.org/10.2118/01-07-02.

17. Howard, J.J. Quantitative estimates of porous media wettability from proton NMR measurements. Magnetic Resonance Imaging, 1998, 16, 529-533. https://doi.org/10.1016/S0730-725X(98)00060-5. 
18. Shkalikov, N.V.; Skirda, V.D.; Archipov, R.V. Solid-like component in the spin-spin NMR-relaxation of heavy oils. Magnetic Resonance in Solids. Electronic Journal, 2006, 8 (1), 38-42.

19. Bryan, J.; Kantzas, A.; Bellehumeur, C. Oil-viscosity predictions from low-field NMR measurements. SPE Reservoir Evaluation E Engineering, 2005, 8, 44-53. https://doi.org/10.2118/89070-PA.

20. Korb, J.P.; Vorapalawut, N.; Nicot, B.; Bryant, R.G. Relation and Correlation between NMR Relaxation Times, Diffusion Coefficients, and Viscosity of Heavy Crude Oils. The Journal of Physical Chemistry, 2015, 119 (43), 24439-24446. https://doi.org/10.1021/acs.jpcc.5b07510.

21. Birdwell, J.E.; Washburn, K.E. Multivariate Analysis Relating Oil Shale Geochemical Properties to NMR Relaxometry. Energy E Fuels, 2015, 29 (4), 2234-2243. https://doi.org/10.1021/ef502828k.

22. Vlasov, V.A.; Zavodovsky, A.G.; Madygulov, M.Sh.; Reshetnikov, A.M. Formation of supercooled water during dissociation of gas hydrates according to the nuclear magnetic resonance method. Earth's Cryosphere, 2011, 4, 83-85 (In Russian).

23. Kleinberg, R.L.; Flaum, C.; Straley, C.; Brewer, P.G.; Malby, G.E.; Peltzer III, E.T.; Friederich, G.; Yesinowski, J.P. Seafloor nuclear magnetic resonance assay of methane hydrate in sediment and rock. Journal of Geophysical Research, 2003, 108 (B3), 13 p.

24. Shumskayte, M.Y.; Glinskikh, V.N., Bortnikova, S.B.; Kharitonov, A.N., Permyakov, V.S. NMR relaxometry laboratory study of fluids taken from boreholes. Bulletin of the Tomsk Polytechnic University. Geo Assets Engineering 2017, 328(2), 59-66 (In Russian).

25. Turakhanov, A. K.; Glinskikh, V.N.; Kashirtsev, V.A.; Fursenko, E.A.; Shumskaite, M.I. The application of the magnetic resonance relaxometry method to express-study of rheological properties and composition of oil and gas condensate. Oil and gas geology. theory and practice 2017, 12(3), 1-15 (In Russian). https://doi.org/10.17353/2070-5379/29_2017.

26. Hürlimann, M.D.; Freed, D.E.; Zielinski, L.J.; Song, Y.Q.; Leu, G.; Straley, C.; Cao Minh, C.; Boyd, A. Hydrocarbon Composition from NMR Diffusion and Relaxation Data. Petrophysics, 2009, 50 (2), 116-129.

27. Zaripov, T.A.; Doroginitsky, M.M.; Gizatullin, B.I.; Abdullin, T.R.; Musin, K.M.; Murzakaev, V.M. The results of studying the viscosity of oil from the fields of the Republic of Tatarstan using the method of nuclear magnetic resonance relaxometry. Karotazhnik, 2015, 253, 3-13 (In Russian).

28. Freedman, R.; Heaton, N. Fluid characterization using nuclear magnetic resonance logging. Petrophysics, 2004, 45, 241-250.

29. Odivanov, V.L; Kurbanov, R.Kh.; Sadykov, I.I.; Kharisov, A.G. Canal Kvant hard-/software system for measuring the composition and flowrate of oil well fluid. Sensors $\mathcal{E}$ Systems 2008, 3, 7-12 (In Russia).

30. Kashaev, R.S. Viscosity Correlations with Nuclear (Proton) Magnetic Resonance Relaxation in Oil Disperse Systems. Applied Magnetic Resonance 2018, 49(3), 1-7. https://doi.org/10.1007/s00723-018-0977-2.

31. Kashaev, R.S.; Kubango, B.E. Flow NMR analyzers for control of well fluid, crude oil and oil dispersion systems; Tambov: LLC "Consulting Company Yucom", 2016, 82 p. (In Russian).

32. Rinaldi, V. A.; Francisca, F. M. Impedance analysis of soil dielectric dispersion (1 MHz-1 GHz). Journal of geotechnical and geoenvironmental engineering 1999, 125(2), 111-121. https://doi.org/10.1061/(ASCE)1090-0241(1999)125:2(111).

33. Bobrov, P.P.; Belyaeva, T.A.; Kroshka, E.S.; Rodionova O.V. Relationship of low-frequency dielectric permittivity with the conductivity of low-salted sand samples. Radio communication technology 2020, 3 (46), 85-94. https://doi.org/10.33286/2075-86932020-46-85-94.

34. Akselrod, S.M. New trends in dielectric logging (based on foreign press materials). Karotazhnik 2012, 4, 78-112 (In Russian).

35. Murav'ev, L.A.; Dolomansky, Yu.K. Software of the NMR relaxometry. Ural Geophysical Gazette, 2010, 1(16), 33-39 (in Russian).

36. Dzhafarov, I.S.; Syngaevsky, P.E.; Khafizov, S.F. Application of the method of nuclear magnetic resonance to characterize the composition and distribution of reservoir fluids; Moscow: Chemistry, 2002, $439 \mathrm{p}$.

37. Abragam, A. The principles of nuclear magnetism; Oxford: Clarendon Press, 1962, $599 \mathrm{p}$.

38. Axelrod, S.M. Nuclear magnetic resonance in oil and gas geology and geophysics; Moscow: Nedra, 1990, 192 p.

39. Dunn, K.J.; Bergman, D.J.; LaTorracca, G.A. Nuclear magnetic resonance. Petrophysical and logging application; London: PERGAMON, 2002, $294 \mathrm{p}$.

40. Tikhonov, A.N.; Goncharsky, A.V.; Stepanov, V.V.; Yagola, A.G. Numerical methods for solving ill-posed problems; Moscow: Nedra, 1992, 232 p.

41. Mezin, A.A.; Shumskayte, M.Y.; Chernova, E.A.; Burukhina, A.I. Physical/chemical properties of oil from Eastern and Western Siberia deposits: integrated study by dielectric spectroscopy and NMR relaxometry methods. Bulletin of the Tomsk Polytechnic University. Geo Assets Engineering 2021, 332(2), 106-115. https://doi.org/10.18799/24131830/2021/2/3047.

42. Brandt, A.A. Investigation of dielectrics at ultrahigh frequencies, Moscow: State publishing house of physical and mathematical literature, $1963,404 \mathrm{p}$.

43. Lapina, A.S.; Bobrov, P.P.; Golikov, N.A.; Repin, A.V.; Shumskayte, M.Y. Hysteresis of the NMR response and the complex relative permittivity of the quartz granules powders and solid sandstones during the water imbibition and drainage. Measurement Science and Technology, 2016, 28, 7 p. https://doi.org/10.1088/1361-6501/28/1/014007.

44. ASTM D5002-19, Standard Test Method for Density, Relative Density, and API Gravity of Crude Oils by Digital Density Analyzer, ASTM International, West Conshohocken, PA, 2019, www.astm.org

45. GOST 33-2000, Petroleum products. Transparent and opaque liquids. Determination of kinematic viscosity and calculation of dynamic viscosity, Interstate Council for Standardization, Metrology and Certification, Minsk, 2008.

46. Epov, M.I.; Bobrov, P.P.; Mironov, V.L.; Repin, A.V. Dielectric relaxation in oil-bearing clayey rocks. Russian Geology and Geophysics 2011, 9, 1028-1034. https://doi.org/10.1016/j.rgg.2011.08.008. 
47. Vasilyeva, M. A.; Gusev, Y.A.; Shtyrlin, V.G.; Greenbaum (Gutina), A.; Puzenko, A.; Ishai, P. B.; Feldman, Y. Dielectric relaxation of water in clay minerals. Clays and Clay Minerals 2014, 62, 1, 62-73. https://doi.org/10.1346/CCMN.2014.0620106. 